\title{
O MITO DE ORIGEM DO MODERNISMO BRASILEIRO FAZ 90 ANOS
}

O que define a brasilidade? Recentemente, a valorização do país enquanto economia emergente vem promovendo um retorno a essa pergunta. A presença do Brasil na mídia internacional traz sempre questionamentos a respeito da imagem do país lá fora. $\mathrm{O}$ ano de 2012 marca os 90 anos da Semana de Arte Moderna quando, há um século atrás, um Brasil, saído da escravidão e da monarquia, inicia seu processo de modernização, que caminha pari passu com a invenção de novas linguagens estéticas e com a criação de uma identidade brasileira. A efeméride motiva uma nova reflexão para problematizar a invenção de uma singularidade brasileira e se o movimento foi, de fato, uma ruptura com o passado.

"Os modernistas entendem que o modernismo produz a mais autêntica e amadurecida vertente cultural no país. Eles partem do pressuposto de que a cultura brasileira e, no limite, o próprio Brasil, tenha brotado de si próprio. O Brasil, na lente modernista, nasce de si mesmo", afirma a socióloga Ana Lúcia de Freitas Teixeira, professora da Universidade Federal de São Paulo (Unifesp), ao pesquisar a emergência do modernismo brasileiro na virada do século XIX para o $\mathrm{XX}$ - cujo mito de origem seria justamente a Semana de 1922.

A sociológa destaca que essa criação do movimento modernista - como uma ruptura com o passado - tende a ser tomada como algo dado nas interpretações canônicas sobre o movimento. $\mathrm{O}$ rompimento entre o modernismo brasileiro e o modernismo português, por exemplo, é silenciado, sem se levar em consideração o jogo de espelhos que se estabelece entre os dois países: a antiga colônia quer se livrar de Portugal e, para tanto, inventa uma imagem da antiga metrópole enquanto país arcaico e atrasado, ignorando - de forma deliberada - Portugal. "Os modernistas brasileiros se interessam por afirmar o rompimento com uma ex-metrópole que é, ela mesma, periférica em relação ao centro irradiador de cultura, naquele momento, que é a França. Os raros momentos em que afirmamos a insignificância de Portugal, naquele momento, serve a um

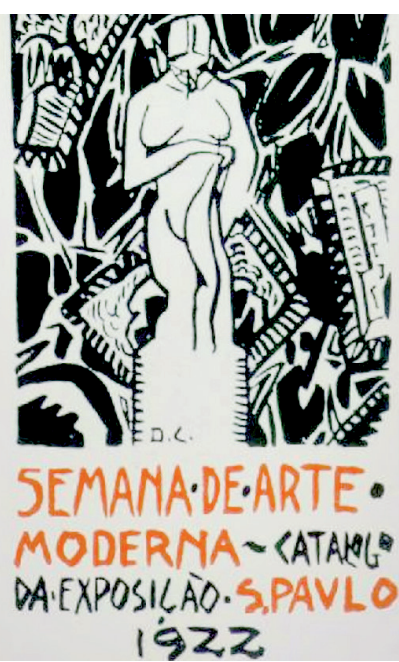
só tempo para soterrarmos a dimensão de ex-colônia e para nos desvencilharmos de um vínculo que nos 'contaminaria' de sua aura de atraso”, diz a socióloga, que analisou cuidadosamente essa configuração em sua tese de doutorado, intitulada "Modernidades
Na escadaria, expoentes da turma da Semana de 22, como ficou conhecido o movimento cultural que agitou 0 Teatro Municipal de São Paulo e a concepção de nação; cartazes de época e as obras (ao lado, no alto) A ventania, de Anita Malfatti, e Abaporu, de Tarsila do Amaral
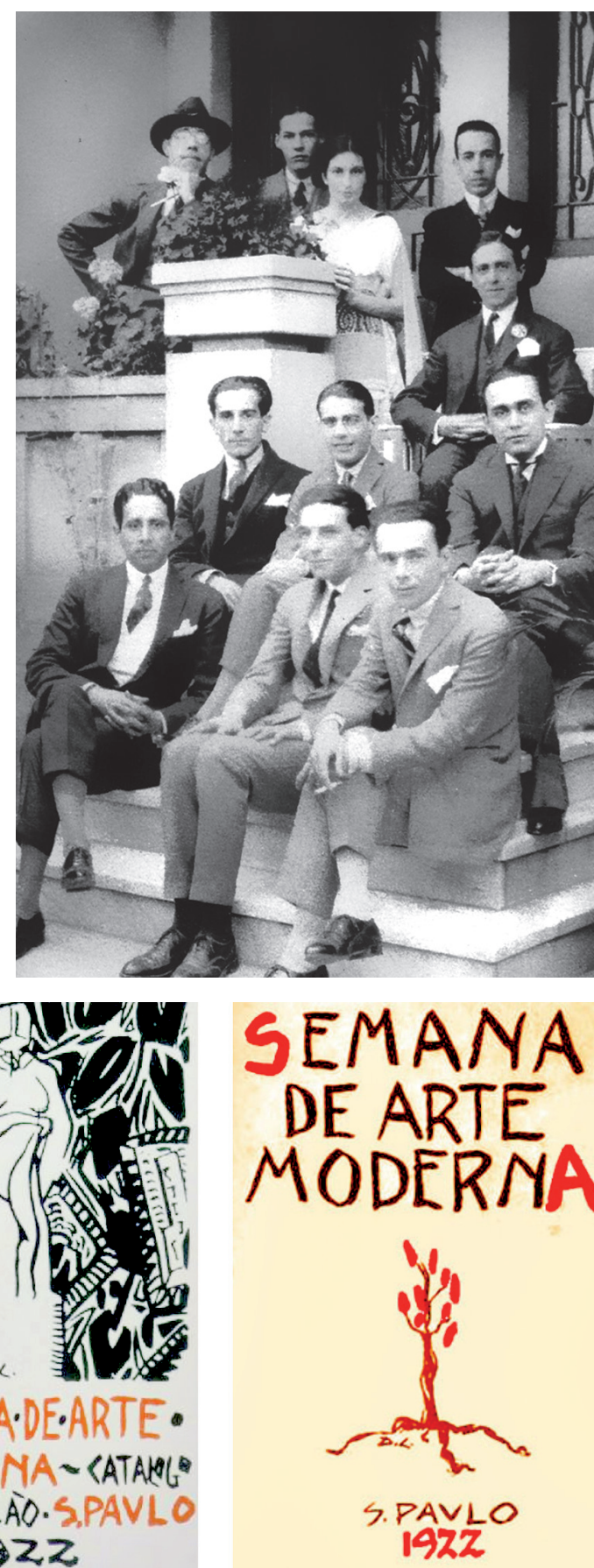

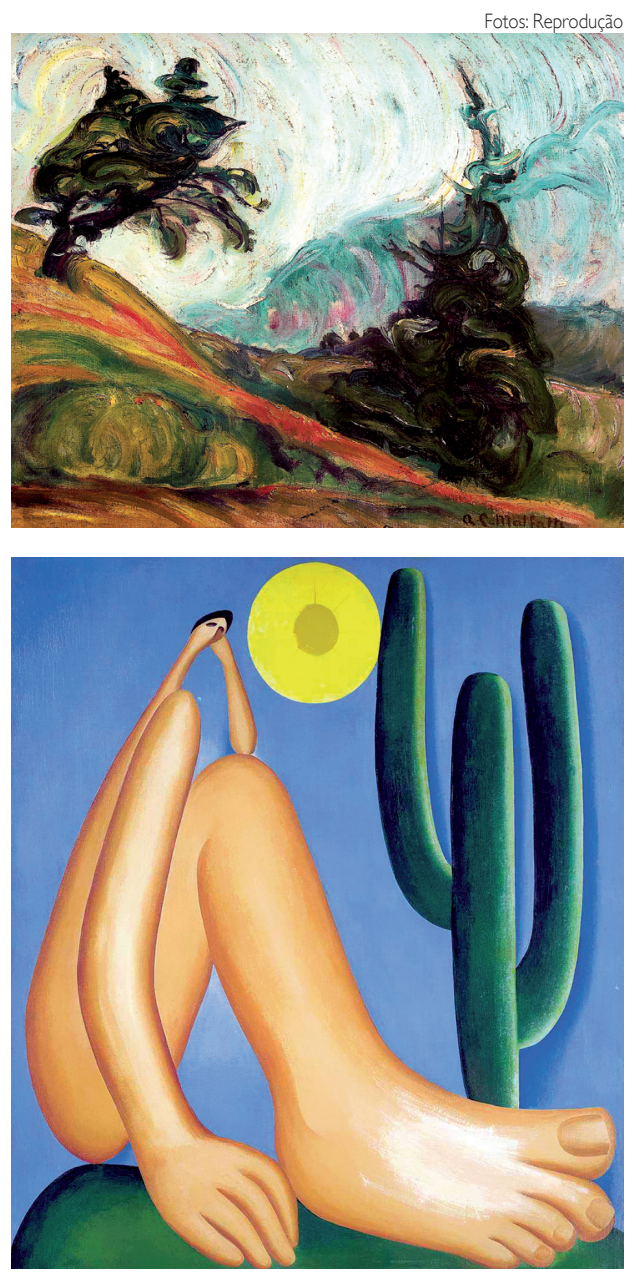

em confronto - as literaturas modernistas brasileira e portuguesa” (USP, 2009).

NACIONALISMO PAULISTA No Brasil, o modernismo caminhou simultaneamente com a modernização do próprio país e, especialmente, com a chamada metropolização paulista. "São Paulo se fez, naquele momento, como laboratório da nacionalidade brasileira”. Ana Lúcia acrescenta ainda que, para compreender a efervescência desse "laboratório", seria necessário desfazer imagens homogeneizadoras em torno de movimentações im- portantes na paisagem da cidade, como aquelas relacionadas à diversidade da migração e da presença dos estrangeiros. Havia imigrantes que eram ricos empresários (Francisco "Ciccillo" Matarazzo é o mais emblemático deles), assim como a imigração de grandes fazendeiros vindos do interior para a capital; imigrantes pobres que se mudavam para o interior paulista, para trabalhar nos cafezais, mas que também não deixavam de marcar presença em vários bairros da capital, presença, aliás, percebida pela literatura modernista em Brás, Bexiga e Barrafunda, de Alcântara Machado, publicado em 1927.

Eram tantos grupos e pessoas circulando pela cidade que a metrópole configurava-se, então, enquanto um espaço sem identidade. "Afinal, São Paulo não era uma cidade nem de negros, nem de brancos e nem de mestiços; nem de estrangeiros e nem de brasileiros; nem americana, nem europeia, nem nativa; nem era industrial, apesar do número crescente das fábricas, nem entreposto agrícola, apesar da importância crucial do café; nem era tropical, nem subtropical; não era ainda moderna, mas já não tinha mais passado. Essa cidade que brotou súbita e inexplicavelmente, como um colossal cogumelo depois da chuva, era um enigma para seus próprios habitantes, perplexos, tentando entendê-lo como podiam, enquanto lutavam para não serem devorados", escreve o historiador Nicolau Sevcenko em Orpheu extático na metrópole (São Paulo: sociedade e cultura nos frementes anos 20)(2003, p. 30, 31), ao recriar o clima dessa emergente paisagem urbana na virada do século XIX para o XX.

Segundo Ana Lúcia, uma das reinvençôes que marca esse processo de urbanização da cidade de São Paulo - e que acontece conjuntamente com a constituição do modernismo e suas expressões estéticas - é o mito bandeirante, criado para se tentar conferir algum tipo de coesão social a esse caldeirão explosivo descrito por Sevcenko. Mito que apaga o passado recente da escravidão, a relação com Portugal, a apropriação de terras (transformadas em propriedades privadas) e o extermínio das populaçôes indígenas: a figura do colonizador é cindida do português, e o bandeirante torna-se um heroico sertanejo desbravador do "interior" do país, torna-se "paulista". Constitui- se, então, um nacionalismo a partir do bandeirante e sua "vocação natural" para liderar, vencer obstáculos eadversidades. Expressão dessa imagem bandeirante dos paulistas, o Monumento às Bandeiras, do escultor Victor Brecheret, é um dos marcos do modernismo: encomendada pelo governo estadual, em 1921, foi inaugurada - juntamente com o Parque Ibirapuera-em 1954, durante o Quarto Centenário de São Paulo.

Entre os modernistas da Semana de 1922, essa valorização da "superioridade paulista” será promovida, principalmente, pelos chamados verde-amarelistas, dentre eles, Plínio Salgado, Menotti del Picchia e Cassiano Ricardo, para os quais São Paulo condensava a identidade brasileira. Mas, a partir desse nacionalismo paulista, é 
possível notar que os modernistas não configuravam um grupo homogêneo. Havia outras vertentes modernistas que não estavam, inclusive, sequer preocupadas com a questão da nação. "Além do Ronald de Carvalho, no Rio de Janeiro, que estava centrado na questão da América, ainda podemos considerar Carlos Drummond de Andrade e Manuel Bandeira, ambos integrantes do movimento modernista. Um mineiro e um pernambucano, ambos se mudaram num certo momento para o Rio, mantiveram estreitos laços com os modernistas paulistas, sobretudo Mário de Andrade, mas nenhum deles têm a nação como preocupação. E a força do cânone que coloca São Paulo no centro do modernismo se expressa pelo fato de que, frequentemente, a crítica dirá de ambos que não eram 'exatamente modernistas', sobretudo no caso do Bandeira e do Drummond da primeira fase", lembra Ana Lúcia Teixeira.

Antropofagia

"ideal bandeirante"

Tome este automóvel

Evá ver o Jardim New-Garden

Depois volte à Rua da Boa Vista

Compre o seu lote

Registre a escritura

Boa firme e valiosa

E more nesse bairro romântico

Equivalente ao célebre

Bois de Bologne

Prestaçôes mensais

Semjuros

O poema acima faz parte do livro Pau Brasil (1925), de Oswald de Andrade, expressão do fino hu- mor desse escritor dirigindo-se com precisão à vida burguesa $\mathrm{da}$ elite paulista, à metropolização da cidade, ao empreendedorismo e ao modo como tudo isso se amalgama no nacionalismo paulista, em seu "ideal bandeirante" que, ironizado no poema, faz com que o mito perca sua eficácia. "A grande preocupação de Oswald de Andrade é com a construção de uma cultura brasileira autônoma. Oswald afirma uma originalidade brasileira pela sátira e pela ironia. Através delas, ele revê o modernismo para recalibrá-lo", afirma Ana Lúcia. Ou seja, Oswald compartilha o projeto de construção da nação que marca o modernismo. Mas seu projeto é complexo, passando pela questão da renovação da linguagem - não é à toa que sua obra será retomada pelos poetas concretistas a partir dos anos 1950 -, por uma reescrita da história e pela criação de uma teoria sobre a singularidade da nação brasileira: a antropofagia.

ZUMBIS ANTROPOFÁGICOS Como pensar, então, o legado do modernismo brasileiro no mundo contemporâneo? Para a psicanalista, curadora e crítica de arte Suely Rolnik, a principal contribuição do modernismo foi valorizar e tornar consciente uma "subjetividade flexível", aberta à incorporação de outros universos culturais, marcada pela experimentação e o improviso, sem manter uma identificação estável e absoluta com qualquer repertório cultural, seja ele europeu ou, mais recentemente, norte-americano. $\mathrm{O}$ problema é que essa "flexibilidade brasileira" estaria, pelo menos desde o fim da ditadura militar, sendo apropriada pelo mercado.

Em Geopolitica da cafetinagem (2008), Rolnik analisa como os movimentos de contracultura das décadas de 1960 e 1970 que reativaram o ideário antropofágico vêm sendo reapropriados pelo capitalismo contemporâneo, que tira vantagem da experimentação e da sua força de criação. Bastaria observar a importância que a arte brasileira adquire no mercado internacional, principalmente a partir dos anos 1990 .

A clonagem do nosso "know-how antropofágico" também torna os brasileiros campeões mundiais na publicidade e nas telenovelas, e faz deles "zumbis antropofágicos": sua potência de criação vira combustível para o regime capitalista contemporâneo, que se abastece, portanto e principalmente, da "plasticidade" e do "jogo de cintura" dos brasileiros, aptos para viver a flexibilidade do fim dos direitos trabalhistas, da informalidade e precarização do trabalho, por exemplo.

"É essa força, assim cafetinada, que com uma velocidade exponencial vem transformando o planeta num gigantesco mercado, e seus habitantes, em zumbis hiperativos incluídos ou trapos humanos excluídos - dois polos entre os quais perfilam os destinos que lhes são acenados, frutos interdependentes de uma mesma lógica”, escreve Rolnik. Diante dessa lógica - a do chamado capitalismo "cognitivo" ou "cultural" - como reativar a potência política da arte e da cultura é a pergunta que fica no ar.

Carolina Cantarino 